\title{
Sentiment Analysis of the Body-Shaming Beauty Vlog Comments
}

\author{
Jajam Haerul Jaman ${ }^{1}$, Hannie ${ }^{2}$, Martina Sari Simatupang ${ }^{3}$ \\ \{jajam.haeruljaman@staff.unsika.ac.id ${ }^{1}$, hannie@staff.unsika.ac.id ${ }^{2}$, \\ martina.sari15086@student.unsika.ac.id $\left.{ }^{3}\right\}$ \\ Department of Computer Science, Singaperbangsa Karawang University, Jl. H.S. Ronggowaluyo \\ Telukjambe Timur, Karawang 41361, Indonesia ${ }^{1,2,3}$
}

\begin{abstract}
Sentiment analysis can be used as a solution to identify body-shaming comments with the classification method using the Naïve Bayes Classifier algorithm. Naïve Bayes Classifier uses the concept of probability of each class in its classification learning. The purpose of this study is to predict or classify comment data based on shaming and non-shaming sentiment classes. The test in this study was carried out with ten different scenarios using the R programming language with RStudio tools which were then evaluated using the confusion matrix to determine the best classifier model. The evaluation results with the confusion matrix found that the best model classifier is a scenario with a comparison of training data and testing data 90:10 and applying to stem at the preprocessing. This scenario achieves an accuracy of $98.48 \%$ with an error rate of $1.52 \%$. Recall is $99.53 \%$, specificity is $66.67 \%$, precision is $98.90 \%$, and F-measure is $99.21 \%$.
\end{abstract}

Keywords: Body Shaming, Naïve Bayes Classifier, Sentiment Analysis

\section{Introduction}

YouTube is seen as a platform for broadcasting, and accommodating cultural discourse of participation and the emergence of a new generation of consumers who are more creative and empowered. Vlogging is one of the dominant forms of content on YouTube [1]. One of the vlog content that is quite popular at the moment is beauty vlog content. According to data from the 2018 ZAP Beauty Index, it is known that Indonesian women in finding references about beauty products by 55\% came from social media Instagram, $41.6 \%$ from YouTube channels and $40.9 \%$ from beauty bloggers.

Indirectly beauty vlogger has strengthened the construction of social reality about how important beauty and appearance are in society. The construction of social reality which becomes a value or reality that is believed without question turns out to be applicable to beauty standards [2]. The image of beauty standards displayed by social media is what triggers others to provide body-shaming comments or negative comments that physically offend either directly or indirectly. Body shaming is very closely related to body image, which is about forming the perception of the ideal body according to the community so that a standard of beauty appears that makes a person feel inferior when unable to reach these standards. Satire which is intentional or not is categorized as something verbal violence which is furthermore commonly referred to as body shaming [3]. 
Sentiment analysis can be used as a solution to detect body-shaming comments by the classification method. Sentiment analysis of comments is done to find out negative comments and positive comments. From this analysis, prevention can be carried out for both victims and perpetrators [4]. There are several classification algorithms such as Naïve Bayes, K-Nearest Neighbor, Decision Tree, or Support Vector Machine. In this study the algorithm that will be used is Naïve Bayes Classifier. Naïve Bayes algorithm uses the concept of probability of each class in its classification learning so that the difference between classes is not large [5].

\section{Background and Related Work}

In recent years there are several studies related to sentiment analysis using text mining with classification method, sentiment analysis on cyberbullying comments using SVM [4] with the lexicon-based approach and without the lexicon-based approach on five percentage split scenarios. This research produces the highest accuracy of 90\% in the 50:50 test scenario and without using the lexicon-based approach. The implementation of the lexicon-based method affects the accuracy results because the use of the lexicon dictionary is still common (not focused on cyberbullying) but the data used are varied, complex and contain many slang languages. Buntoro [6] compared the Naïve Bayes classification algorithm and Support Vector Machine, it is known that Naïve Bayes has an average accuracy value of $95 \%$ and is superior to Support Vector Machine. According to Buntoro, Naïve Bayes tends to be more stable because of the probability based on the appearance of words in a sentence. Ipmawati, Kusrini and Lutfi [7] made comparisons of the text mining classification algorithm using Naïve Bayes, Support Vector Machines and K-Nearest Neighbors. As a result, Naïve Bayes and Support Vector Machine have the same accuracy level of $78.5 \%$, but Naïve Bayes has an AUC value of 0.869 superior to SVM 0.786 and KNN 0.572 .

Rachmat and Lukito [5] suggest that stemming is needed at the preprocessing stage to test whether or not it has an influence on the results of classification accuracy. Faradhillah's research results [8] say that stop words removal at the preprocessing stage is very influential on the results of the Naïve Bayes classification. Based on the results of previous studies, this study will use the Naïve Bayes algorithm and conduct tests with different scenarios, namely comparing the proportion of training and test data and comparing the implementation using Nazief-Adriani stemming and without stemming in the preprocessing stage.

\section{Methodology}

The methodology used in this study is the Cross-Industry Standard Process for Data Mining (CRISP-DM) which consists of six outlines of the research cycle such as, Business Understanding, Data Understanding, Data Preparation, Modeling, Evaluation, and Deployment. The application of text mining techniques in this study is in the data preparation phase, in that phase various steps will be taken to prepare text mining. Furthermore, the implementation of Naive Bayes is carried out in the modeling phase with percentage split testing. The methodology used in this research shows in Figure 1. 


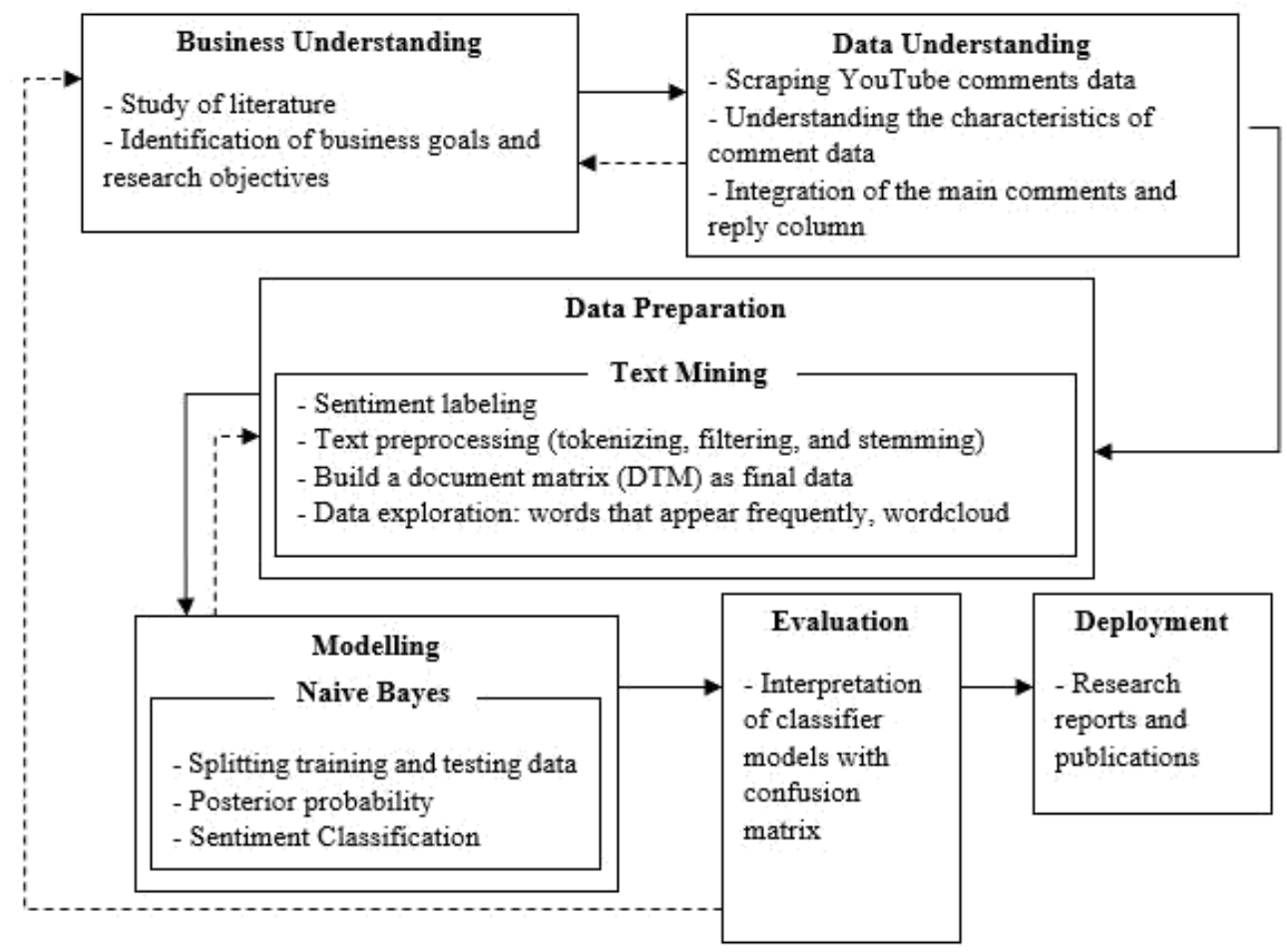

Fig. 1. Research flow.

\section{Results}

\subsection{Business understanding}

Business understanding is achieved by studying literature in studying theories relevant to text mining and the Naïve Bayes algorithm used for classification and understanding sentences that include intimidation about body image.

\subsection{Data understanding}

Collect initial data. Comment data collection is done through a site that can scrap your YouTube videos for free, namely ytcomments.klostermann.ca. At the site, the scrape data can be stored in the form of JSON or CSV. The comment data used comes from one of the beauty vlogger makeup video tutorials. Data collected from the date of uploading videos April 28, 2018, until February 24, 2019, were 33,044 data. 


\subsection{Data preparation}

Data preparation is a stage that covers all text mining activities and builds a final dataset so that it will be ready to make a classifier model. At this stage, 4 other steps will be carried out such as sentiment labeling, preprocessing, transformation, and data exploration.

Sentiment labelling. Determination of sentiment class on each comment data is done manually by the researcher which is then validated by the supervisor, namely Wienike Dinar Pratiwi, who is an Indonesian Language Lecturer at Singaperbangsa Karawang University. The results of the manual labeling by researchers of a total of 33,044 comments, known composition of shaming sentiments were 1,157 comments and non_shaming sentiments were 31,887 comments. However, after being validated there was a change in sentiment composition to 986 shaming sentiments and as many as 32,058 non_shaming sentiments.

Text preprocessing. This stage consists of data cleaning, case folding, tokenizing, normalization, remove letter duplication, stopwords removal, stemming, remove whitespace, and remove NA.

Transformation. Data transformation in text mining is changing the form of data into a document term matrix (DTM). DTM is a two-dimensional matrix measuring $\mathrm{n} x \mathrm{p}$ with documents as rows and words (terms) as columns whose elements are the number of words in a document. The function of the DTM is to be able to represent the topic of a document in the presence of a significant word frequency. The formation of a DTM is done at the same time as the TF-IDF term weighting, which is an evaluation to find out how important a word or term is in a collection of documents or corpus. The formula for calculating word weights with TFIDF is shown on Equation 1.

$$
w i j=t f i j \times(\log ()+1)
$$

wij is the weight of term tj for documents, tfij is the number of occurrences of term $\mathrm{tj}$ in documents, $\mathrm{D}$ is the number of all documents in the database, and dfj is the number of documents containing term tj. Table 1 below is an example of a document term matrix that is formed.

Table 1. Document Term Matrix with TF-IDF.

\begin{tabular}{cccccc}
\hline \multirow{2}{*}{ Docs } & \multicolumn{5}{c}{ Terms } \\
\cline { 2 - 6 } & jelek & maaf & muka & $\ldots$. & nonton \\
\hline 1 & 2.0830 & 2.1523 & 0 & $\ldots$. & 0 \\
2 & 0 & 0 & 1.3613 & $\ldots$. & 0 \\
$\ldots$. & $\ldots$ & $\ldots$. & $\ldots$. & $\ldots$. & 0 \\
14749 & 0 & 0.2268 & 0.1985 & $\ldots$. & 0 \\
$\ldots$. & $\ldots$ & $\ldots$. & $\ldots$. & $\ldots$. & 0 \\
32859 & 0 & 0 & 0 & $\ldots$. & 0.9466 \\
\hline
\end{tabular}

Data exploration. Data exploration at this stage aims to determine the characteristics of the data and visualize. 
The bar chart on Figure 2 and word cloud on Figure 3 below presents a visualization of data from the 56 most frequently occurring words. Makeup is the word that most often appears with a number of more than 2000 times.

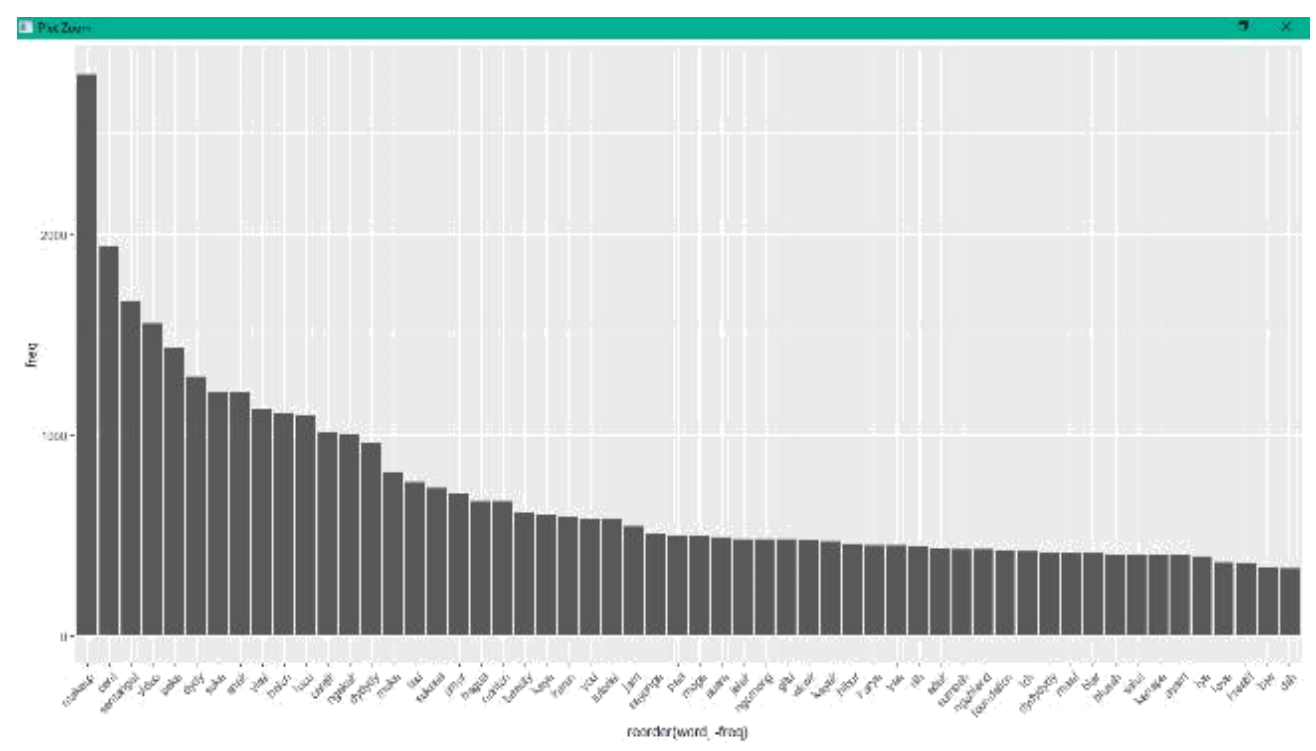

Fig. 2. The most frequently occurring words bar chart.

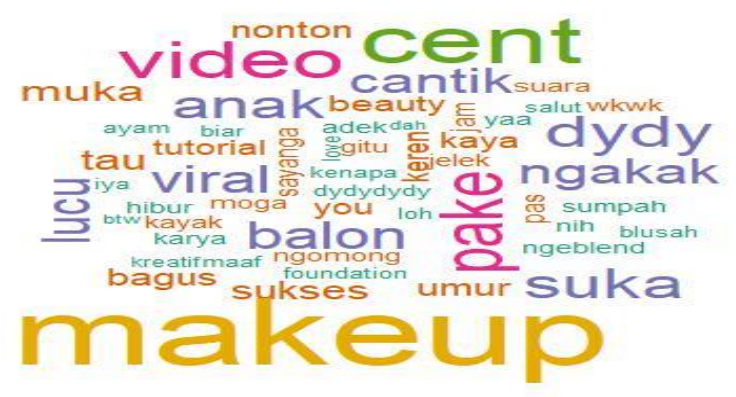

Fig. 3. Word cloud.

\subsection{Modeling}

The modeling stage is the stage for selecting modeling techniques from the classification algorithm that will be used to form the classifier model. The text classification algorithm chosen is the Naive Bayes Classifier which is used to achieve the initial objectives of this study. The test is carried out with ten experimental scenarios to find out which model is better. Based on previous research references, the scenario will be made by comparing the proportion of training data and test data, namely 50:50, 60:40, 70:30, 80:20, 90:10, and by applying stemming and without stemming in the preprocessing process. The results can be seen in 
Table 2, Table 3, Table 4, Table 5, Table 6, Figure 4, Figure 5, Figure 6, Figure 7, and Figure 8 below.

Table 2. Accuracy results.

\begin{tabular}{|c|c|c|}
\hline \multirow{2}{*}{ Split } & \multicolumn{2}{|c|}{ Accuracy (\%) } \\
\cline { 2 - 3 } & Without Stemming & With Stemming \\
\hline $50: 50$ & 97,38 & 97,38 \\
\hline $60: 40$ & 97,46 & 97,51 \\
\hline $70: 30$ & 97,55 & 97,57 \\
\hline $80: 20$ & 97,67 & 97,76 \\
\hline $90: 10$ & 97,9 & $\mathbf{9 8 , 4 8}$ \\
\hline \multicolumn{2}{|c|}{ *bold is the highest number } \\
\hline
\end{tabular}

Table 3. Recall results.

\begin{tabular}{|c|c|c|}
\hline \multirow{2}{*}{ Split } & \multicolumn{2}{|c|}{ Recall (\%) } \\
\cline { 2 - 3 } & Without Stemming & With Stemming \\
\hline $50: 50$ & 99,3 & 99,31 \\
\hline $60: 40$ & 99,36 & 99,43 \\
\hline $70: 30$ & 99,34 & 99,39 \\
\hline $80: 20$ & 99,37 & 99,48 \\
\hline $90: 10$ & 99,47 & $\mathbf{9 9 , 5 3}$ \\
\hline \multicolumn{3}{|c|}{ *bold is the highest number } \\
\hline
\end{tabular}

Table 4. Specificity results.

\begin{tabular}{|c|c|c|}
\hline \multirow{2}{*}{ Split } & \multicolumn{2}{|c|}{ Spesificity (\%) } \\
\cline { 2 - 3 } & Without Stemming & With Stemming \\
\hline $50: 50$ & 38,58 & 38,39 \\
\hline $60: 40$ & 40,75 & 40,28 \\
\hline $70: 30$ & 44,75 & 43,83 \\
\hline $80: 20$ & 45,67 & 45,19 \\
\hline $90: 10$ & 50,48 & $\mathbf{6 6 , 6 7}$ \\
\hline \multicolumn{3}{|c|}{ *bold is the highest number } \\
\hline
\end{tabular}

Table 5. Precision results.

\begin{tabular}{|c|c|c|}
\hline \multirow{2}{*}{ Split } & \multicolumn{2}{|c|}{ Precision (\%) } \\
\cline { 2 - 3 } & Without Stemming & With Stemming \\
\hline $50: 50$ & 98,01 & 98 \\
\hline $60: 40$ & 98,03 & 98,02 \\
\hline $70: 30$ & 98,14 & 98,11 \\
\hline $80: 20$ & 98,24 & 98,23 \\
\hline $90: 10$ & 98,38 & $\mathbf{9 8 , 9 0}$ \\
\hline \multicolumn{2}{|c|}{ *bold is the highest number } \\
\hline
\end{tabular}


Table 6. F-measure results.

\begin{tabular}{|c|c|c|}
\hline \multirow{2}{*}{ Split } & \multicolumn{2}{|c|}{ F-measure (\%) } \\
\cline { 2 - 3 } & Without Stemming & With Stemming \\
\hline $50: 50$ & 98,65 & 98,65 \\
\hline $60: 40$ & 98,69 & 98,72 \\
\hline $70: 30$ & 98,73 & 98,74 \\
\hline $80: 20$ & 98,8 & 98,85 \\
\hline $90: 10$ & 98,92 & $\mathbf{9 9 , 2 1}$ \\
\hline \multicolumn{2}{|c|}{ *bold is the highest number } \\
\hline
\end{tabular}

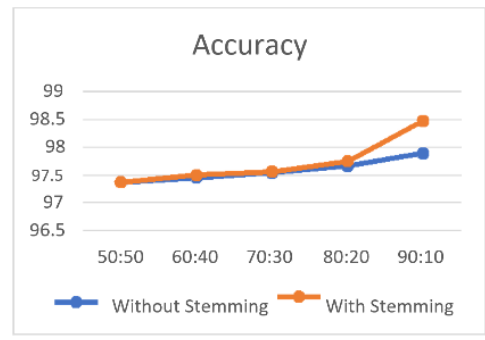

Fig. 4. Accuracy results graph.

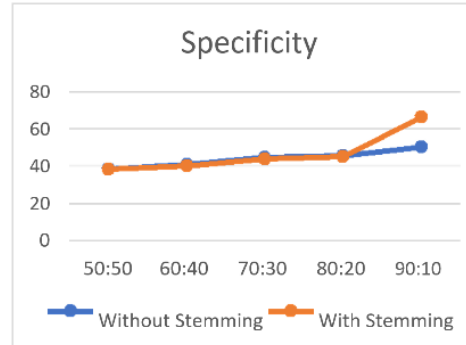

Fig. 6. Specificity results graph.

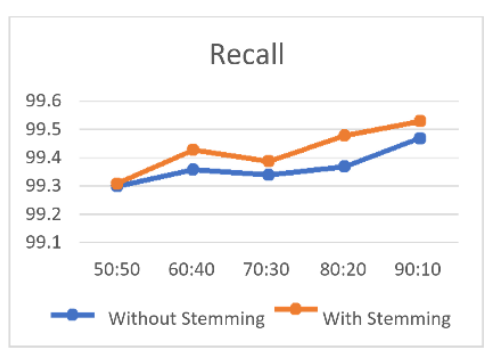

Fig. 5. Recall results graph.

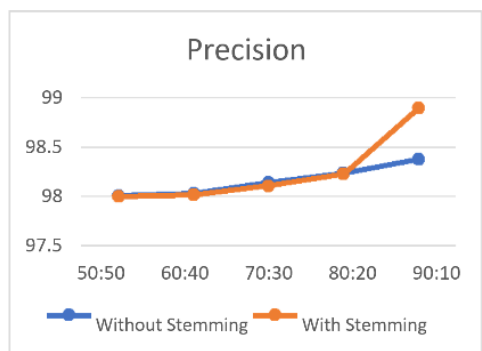

Fig. 7. Precision results graph. 


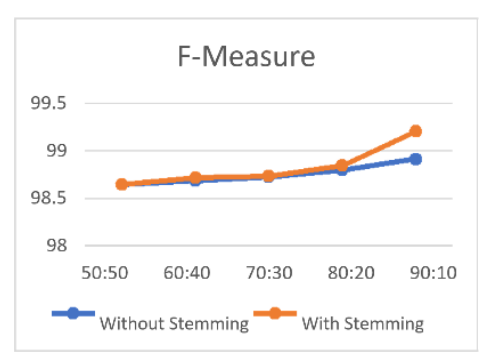

Fig. 8. F-measure results graph.

The process of building the model besides using the Naive Bayes Classifier algorithm, Laplace smoothing is also applied to avoid the possibility of a zero-word probability. In the classification process, Naive Bayes works by calculating the probability of each word appearing in the training document. The following Figure 9 is an example of calculating the probability of the appearance of a word or which is a classifier model formed from scenario 10:

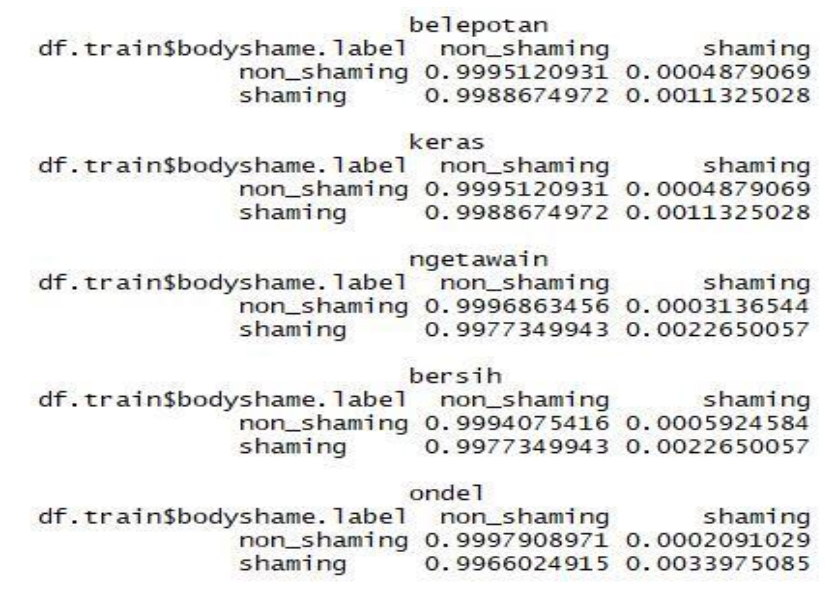

Fig. 9. Posterior probability of the occurrence of words.

\subsection{Evaluation}

The ten classification models that are formed based on each scenario will then be evaluated for the resulting performance. Evaluation is carried out to assess whether the resulting modeling is good or not. The evaluation is carried out in-depth with the aim that the modeling results are in line with the objectives to be achieved in the business understanding stage. Evaluation is measured using a confusion matrix. Comparison of classifier model performance can be seen in Table 7 . 
Table 7. Comparison of model classifier performance.

\begin{tabular}{|c|c|c|c|c|c|c|c|c|c|c|}
\hline $\begin{array}{c}\text { Percentage } \\
\text { Split }\end{array}$ & Stemm-ing & Accuracy & & Recall & & Specificity & & Precision & & F1 \\
\hline & & $97,38 \%$ & - & $99,3 \%$ & - & $38,58 \%$ & & $98,01 \%$ & & $98,65 \%$ \\
\hline $\mathbf{5 0 : 5 0}$ & $\checkmark$ & $97,38 \%$ & $=$ & $99,31 \%$ & $\Delta$ & $38,39 \%$ & $\nabla$ & $98 \%$ & $\nabla$ & $98,65 \%$ \\
\hline & & $97,46 \%$ & $\Delta$ & $99,36 \%$ & $\Delta$ & $40,75 \%$ & $\Delta$ & $98,03 \%$ & $\Delta$ & $98,69 \%$ \\
\hline 60:40 & $\checkmark$ & $97,51 \%$ & $\bar{\Delta}$ & $99,43 \%$ & $\bar{\Delta}$ & $40,28 \%$ & $\bar{\nabla}$ & $98,02 \%$ & $\bar{\nabla}$ & $98,72 \%$ \\
\hline & & $97,55 \%$ & $\Delta$ & $99,34 \%$ & $\bar{\nabla}$ & $44,75 \%$ & $\Delta$ & $98,14 \%$ & $\Delta$ & $98,73 \%$ \\
\hline 70:30 & $\checkmark$ & $97,57 \%$ & $\Delta$ & $99,39 \%$ & $\Delta$ & $43,83 \%$ & $\bar{\nabla}$ & $98,11 \%$ & $\nabla$ & $98,74 \%$ \\
\hline & & $97,67 \%$ & $\bar{\Delta}$ & $99,37 \%$ & $\bar{\nabla}$ & $45,67 \%$ & $\Delta$ & $98,24 \%$ & $\Delta$ & $98,8 \%$ \\
\hline 80:20 & $\checkmark$ & $97,76 \%$ & $\Delta$ & $99,48 \%$ & $\Delta$ & $45,19 \%$ & $\nabla$ & $98,23 \%$ & $\nabla$ & $98,85 \%$ \\
\hline \multirow{2}{*}{$: 10$} & & $97,9 \%$ & $\boldsymbol{\Delta}$ & $99,47 \%$ & $\nabla$ & $50,48 \%$ & $\boldsymbol{\Delta}$ & $98,38 \%$ & $\Delta$ & $98,92 \%$ \\
\hline & $\checkmark$ & $98,48 \%$ & $\Delta$ & $99,53 \%$ & $\Delta$ & $66,67 \%$ & $\boldsymbol{\Delta}$ & $98,90 \%$ & $\Delta$ & $99,21 \%$ \\
\hline
\end{tabular}

Based on Table 7 it can be analyzed that the accuracy of each scenario continues to increase with each change in the proportion of training and test data. Recall decreased by $0.09 \%$ when changing the proportion of data from 60:40 (with stemming) to 70:30 (without stemming). This percentage decrease occurs when scenarios with stemming are compared to without stemming at different data proportions. Specificity is also found to be a decrease in percentage each time the scenario moves without stemming from the scenario with stemming. Precision also experiences a percentage decrease every time a scenario moves without stemming from a scenario with stemming. F1 or F-measure does not decrease in percentage in each scenario, but there is an increase in percentage as in the accuracy matrix. A comparison of the performance of this evaluation matrix will be presented in graphical form as in Figure 10 .

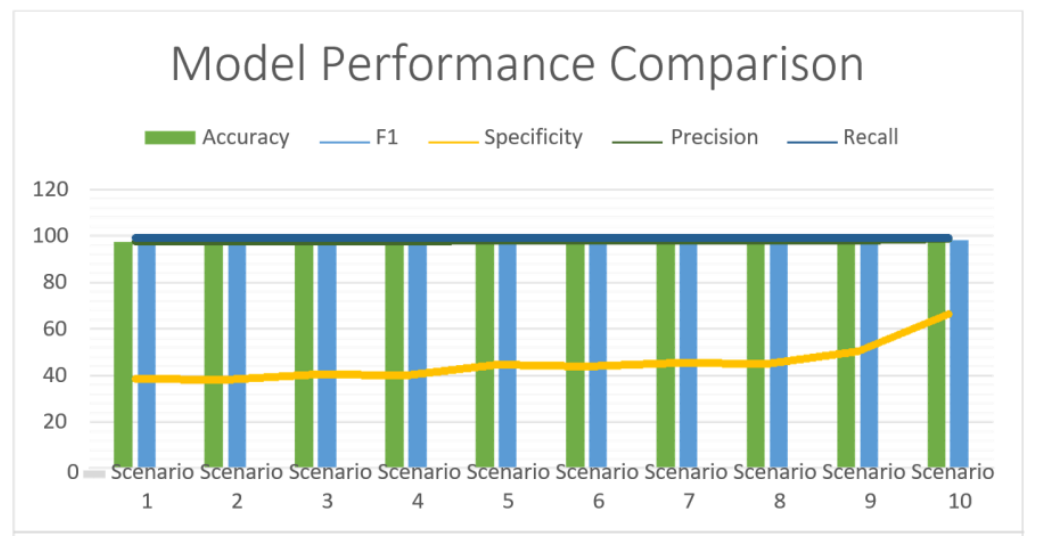

Fig. 10. Model performance comparison. 


\subsection{Deployment}

This research has carried out all steps in the CRISP-DM research methodology. The Naive Bayes Classifier algorithm successfully classifies and makes good models with several test scenarios. After several test scenarios are evaluated, it is known that the tenth test scenario is the best model. The best model performance with the comparison of training data and 90:10 test data and applying the Nazief-Adriani stemming algorithm achieved an accuracy value of $98.48 \%$ with an error rate of $1.52 \%$. The recall reached $99.53 \%$, the specificity was $66.67 \%$, the precision reached $98.90 \%$, and the F-measure value was $99.21 \%$. Then the final report is made after all stages in the research methodology have been completed properly. Reports are made in the form of paper and presentation slides.

\section{Conclusions}

The performance of the Naïve Bayes algorithm in classifying body-shaming comments with the best classifier model is in the 90:10 scenario test and applying the Nazief-Adriani stemming algorithm. The classifier model was evaluated using a confusion matrix with an accuracy of $98.48 \%$, recall $99.53 \%$, specificity $66.67 \%$, precision $98.90 \%$ and $\mathrm{F} 199.21 \%$.

Future studies can be compared with other classification algorithms, also using more data shaming so that it can be added to the shaming sentiment class according to its categories, for example, eye shaming, fat shaming, thin shaming, and others.

\section{References}

[1] Mahameruaji, J. N., Puspitasari, L., Rosfiantika, E., Rahmawan, D.: Bisnis vlogging dalam industri media digital di Indonesia. Jurnal Ilmu Komunikasi. Vol. 15. No. 1. pp. 61-74 (2018)

[2] Satipah, H. R.: Role mode para beauty vlogger dalam representasi kecantikan (studi kasus pada mahasiswa di Universitas Sumatera Utara). (Thesis). University of Sumatera Utara, Medan, Indonesia (2018)

[3] Putri, B. A. S., Kuntjara, A. P., Sutanto, R. P.: Perancangan kampanye "Sizter's Project" sebagai upaya pencegahan body shaming. Jurnal DKV Adiwarna. Vol. 1. No. 12. pp. 1-9 (2018)

[4] Luqyana, W. A., Cholissodin, I., Perdana, R. S.: Analisis sentimen cyberbullying pada komentar Instagram dengan metode klasifikasi support vector machine. Jurnal Pengembangan Teknologi Informasi dan Ilmu Komputer. Vol. 2. No. 11. pp. 4704-4713 (2018)

[5] Lukito, Y.: Deteksi komentar spam Bahasa Indonesia pada Instagram menggunakan Naive Bayes. Ultimatics: Jurnal Teknik Informatika. Vol. 9. No. 1. pp. 50-58 (2017)

[6] Buntoro, G. A.: Analisis sentimen calon gubernur DKI Jakarta 2017 di Twitter. Integer Journal. Vol. 2. No. 1. pp. 32-41 (2017)

[7] Ipmawati, J.: Komparasi teknik klasifikasi teks mining pada analisis sentimen. Indonesian Journal on Networking and Security. Vol. 6. No. 1. pp. 28-36 (2017)

[8] Faradhillah, N. Y., Kusumawardani, R. P., \& Hafidz, I.: Eksperimen sistem klasifikasi analisa sentimen Twitter pada akun resmi Pemerintah Kota Surabaya berbasis pembelajaran mesin. Seminar Nasional Sistem Informasi Indonesia, Surabaya (2016) 